\title{
On Edge Addition Problem with some graphs
}

\author{
Alaa A. Najim Zainab A. H. Al-Hassan \\ Departement of Mathematics \\ University of Basrha College of Science
}

Recived : $16 \backslash 10 \backslash 2017$

Revised : 30\10\2017

Accepted : 6\12\2017

Available online : $\quad 24 / 1 / 2018$

DOI: $10.29304 / j q c m .2018 .10 .1 .344$

\begin{abstract}
The two questions that: how many edges at least have to be added to the network to ensure the message $d$ within the effective bounds, and how large message delay will be increased when faults occur, can re-write this problem as: What the minimum diameter of a connected graph obtained from a graph of diameter $d$ after adding $t$ extra edges, this problem called "Edge Addition Problem". In this paper we find some exact values to above problem by using some special graphs (Line Graph, Bipartite graph, and complete Bipartite graph).
\end{abstract}

Key words: diameter; altereded graph; edge addition problem.

\section{Computer subject classification :}

\section{Introduction}

Graph Theory is a basic and powerful mathematical tool for a wide rang of application. Many emerging problems in various fields, such as chemistry, industrial and electrical engineering, management of transport planning, marketing and education can pose graph theory problems [1, 2]. In network communication, the topology of the delivery network can be modeled by a graph. Conversely, any graph can also be considered as a topological structure for some interconnection networks [3, 4]. Historically, the first paper on the graph theory was written by Euler in 1736 [2]. W, Rose [5] in 1892, submitted the first representation of the problem as a graph in order to solved. More historical information about the graph theory can be found in F R. K. Chung and M. R. Garey (1984), where they introduction the "Edge Addition Problem" and "Edge Deletion Problem"[6]. There are many authors tried to prove the two problems by find the exact values or bound to these problems, for example A. A. Schoone et.el. (1987) [7], Z. G. Deng and J.-M. Xu (2004) [8], H. -X. Ye and C. 
Yang (2009) [9], A. A. Najim (2005) [10], Y.Z. Wu (2006) [11], S. A. AL-Bachary (2009) [12]. S. A. AL-Maliky (2013) [13]. In this paper we will find exact values to $P(t, d)$ for some $t$ and $d$ by using new teachings. All the authors use the path of graph (with some diameter) to prove the edge addition problem, i.e. the problem became "find a minimum diameter of a connected graph obtained from a graph of diameter $d$ after adding $t$ extra edges".

Theorem (1):- $P(t, 7)=2, t=4,5$

Proof:- Let $t=4, d=7$ and $P=\left(x_{0}, x_{1}, \ldots\right.$, $x_{7}$ ) be simple path of length 7 . The vertices $x_{1}, x_{2}, x_{4}, x_{6}$ partion $P$ in to five segments

$$
\begin{gathered}
P_{1}=P\left(x_{0}, x_{1}\right), P_{2}=P\left(x_{1}, x_{2}\right), \\
P_{3}=P\left(x_{2}, x_{4}\right), P_{4}=P\left(x_{4}, x_{6}\right), \\
P_{5}=P\left(x_{6}, x_{7}\right)
\end{gathered}
$$

Let $G$ be altereded graph obtain from path plus four extra edges.

$e_{1}=\left(x_{0}, x_{4}\right), e_{2}=\left(x_{4}, x_{7}\right), e_{3}=\left(x_{2}, x_{6}\right)$,

$e_{4}=\left(x_{1}, x_{6}\right)$

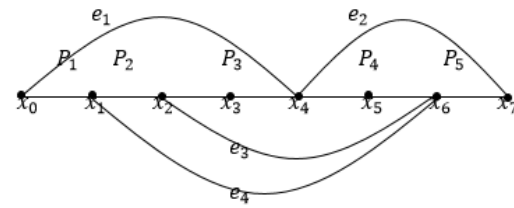

Define seven cycles as follows:

$C^{1}=P_{1} \cup P_{2} \cup P_{3}+e_{1}, C^{2}=P_{1} \cup P_{4}+e_{4}+$ $e_{1}, C^{3}=P_{1} \cup P_{5}+e_{4}+e_{2}+e_{1}, C^{4}=P_{2}+$ $e_{3}+e_{4}, C^{5}=P_{3} \cup P_{4}+e_{3}, C^{6}=P_{3} \cup P_{5}+$ $e_{3}+e_{2}, C^{7}=P_{4} \cup P_{5}+e_{2}$

It is easy to see that,

$$
\begin{array}{ll}
\varepsilon\left(P_{i}\right)=1 & \text { for } i=1,2,5, \text { and } \\
\varepsilon\left(P_{i}\right)=2 & \text { for } i=3,4
\end{array}
$$

Thus we have

$$
\begin{array}{ll}
\varepsilon\left(C^{i}\right)=5 & \text { for } i=1,2,3,5,6 \\
\varepsilon\left(C^{i}\right)=4 & \text { for } i=7 \\
\varepsilon\left(C^{i}\right)=3 & \text { for } i=4
\end{array}
$$

It is easy to see that any two vertices $x$ and $y$ of $G$, are connected in some cycle $C^{i}$ as define above. $\operatorname{Max}\left\{d\left(C^{i}\right): 1 \leq i \leq 7\right\} \leq\left\lfloor\frac{5}{2}\right\rfloor=2$. We get, $P(4,7) \leq d(G) \leq 2$. Now from [8] $\left(\left\lceil\frac{d}{t+1}\right\rceil \leq P(t, d) \leq\left\lceil\frac{d}{t+1}\right\rceil+\right.$ 1) (1) we have $P(4,7) \geq$ $\left\lceil\frac{7}{5}\right]$. Thus, $P(4,7)=2$. From [12] $(P(t, d) \geq$ $P\left(t^{\prime}, d\right)$ if $\left.t \leq t^{\prime}\right)$,

we get: $P(5,7)=2$

Theorem (2):- $P(5,8)=3$

Proof:- Let $P=\left(x_{0}, x_{1}, \ldots, x_{8}\right)$ be an $\left(x_{0}, x_{8}\right)$ path and $G$ an altereded graph obtained from $P$ pluse 5 extra edges and having diameter $d(G)=P(5,8)$. Assum to the contrary $d(G) \leq 2$. If $d(G)=1$, then the number of the extra edges is equal to $t \geq 7+6+\cdots+1=$ 28 , this is contradiction.

Now assume $d(G)=2$. Let $x_{i}$ be a smallest numbered vertex that $G$ has no edge $\left(x_{i}, x_{j}\right)$ with $j>i+1$. Thus, for each $j=0,1, \ldots, i-$ 1 , there exists an $j^{\prime}(\geq j+2)$ such that $\left(x_{j^{\prime}}, x_{j}\right) \in E(G)$ is extra edge, and so such edges are at least $i$.

Since $d(G)=2$, we must be able to reach every other vertex in two steps from $x_{i}$. Hence we need edges $\left(x_{i}, x_{j}\right)$ for all $i+3 \leq j \leq 8$ for some $j^{\prime} \leq j-2$. Then we have two case:

a) suppose $\left(x_{i-1}, x_{j}\right)$ is no extra edge but $\left(x_{i}, x_{j^{\prime}}\right)$ is an extra for some $j^{\prime} \leq i+1$. Then $\left(x_{i}, x_{j^{\prime}}\right)$ and $\left(x_{j^{\prime}}, x_{j}\right)$ are extra edges thus $t \geq i+(9-(i+3))=t+1$,

this is contradiction.

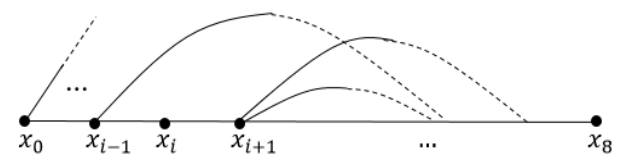

b) suppose $\left(x_{i-1}, x_{j}\right)$ and $\left(x_{i}, x_{j}^{\prime}\right)$ are extra edges for some $j^{\prime}=i-1$. Then some vertices $\left(x_{i+2}, x_{i+3}, \ldots, x_{8}\right)$ need at least one new extra edges to reached any other vertex of the path by at most 2 steps. Thus we have

$$
t \geq i+(9-(i+3)-1)+1=t+1
$$


Alaa .A/ Zainab .A

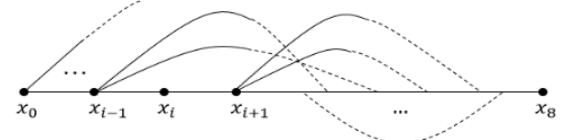

where the appearance of $(-1)$ is because that there is an extra edge $\left(x_{i-1}, x_{j}\right)$ in the first $(i)$ extra edge when $j^{\prime}=i-1$.

But this is contradiction. Thus $P(5,8) \geq 3$ from inequality (1) $P(5,8) \leq\left\lceil\frac{8}{6}\right\rceil+1=3$. Thus $P(5,8)=3$.

Theorem (3):- $P\left((n-1)^{2}, 2 n-1\right)=2$,

$$
n \geq 2
$$

Proof:-Let $K_{n, n}$ be an equally complete bipartite graph with bipartion $\{X, Y\}, X=$ $\left\{x_{1}, x_{2}, \ldots, x_{n}\right\}, Y=\left\{y_{1}, y_{2}, \ldots, y_{n}\right\}, \quad|X|=$ $n,|Y|=n$,

$$
E\left(K_{n, n}\right)=n^{2}, V\left(K_{n, n}\right)=2 n, d\left(K_{n, n}\right)=2
$$
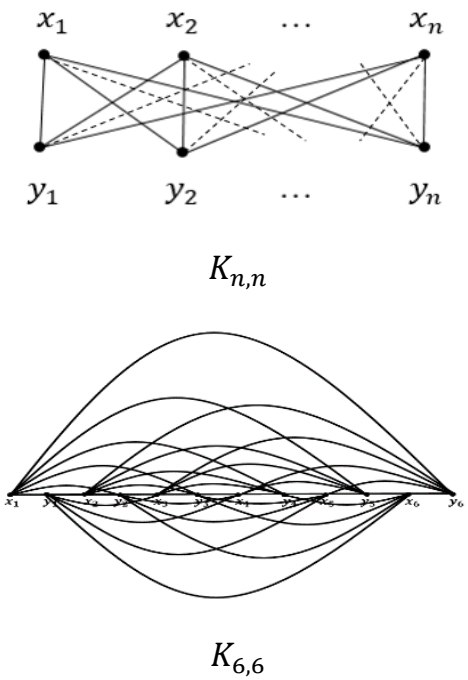

Let $P=\left(x_{1}, y_{1}, x_{2}, y_{2}, \ldots, x_{n}, y_{n}\right)$. Then $P$ is a longest path in $K_{n, n}$.

$d(P)=V\left(K_{n, n}\right)-1=2 n-1$

$G$ an altereded graph with diameter $d(G)=$ $P(t, d)$ optained from the path $P$ pluse $t$ extra edges such that $G \cong K_{n, n}$ then $d(G)=2$ and $t=E\left(K_{n, n}\right)-d(P)=n^{2}-2 n+1$

$$
=(n-1)^{2}
$$

Now we wanted to prove that $P((n-$ $\left.1)^{2}, 2 n-1\right)=2$ by two ways

1) $d\left(K_{n, n}\right)=2 \rightarrow P\left((n-1)^{2}, 2 n-1\right) \leq 2$

Either $P\left((n-1)^{2}, 2 n-1\right)=1$ or

$$
P\left((n-1)^{2}, 2 n-1\right)=2
$$

If $\quad P\left((n-1)^{2}, 2 n-1\right)=1$ this is contradiction (since the graph not complete).

Then $P\left((n-1)^{2}, 2 n-1\right)=2$.

2) If $n=2$ then from [8] (for $d \geq 2, P(1, d)=$ $\left.\left\lfloor\frac{d+1}{2}\right\rfloor\right), P(1,3)=2$

If $n=3$ then from [13] (for $t=4,5$ and $4 \leq d \leq t+1, P(t, d)=2), P(4,5)=2$

If $\quad n \geq 4$ then $P\left((n-1)^{2}, 2 n-1\right) \leq$ $\left\lceil\frac{2 n-3}{(n-1)^{2}+1}\right\rceil+1=\left\lceil\frac{2 n-3}{n^{2}-2 n+2}\right\rceil+1$

Since $n \geq 4$

$$
\begin{aligned}
n^{2} \geq 4 n & \rightarrow n^{2}>4 n-3 \\
& \rightarrow n^{2}-2 n>2 n-3 \\
& \rightarrow n^{2}-2 n+2>2 n-3
\end{aligned}
$$

Then from [12] (for $\frac{r(r-1)}{2} \leq t \leq \frac{(r-1)(r+2)}{2}, r \geq 4$ and $r+1 \leq$ $d \leq t+3$,

$P(t, d)=2$

$P\left((n-1)^{2}, 2 n-1\right) \leq 2$.

Either $P\left((n-1)^{2}, 2 n-1\right)=1$ or

$$
\begin{aligned}
P\left((n-1)^{2}, 2 n-1\right) & =2 \\
\text { If } \quad P\left((n-1)^{2}, 2 n-1\right) & =1 \quad \text { this is }
\end{aligned}
$$
contradiction, (since the graph not complete).

Then $P\left((n-1)^{2}, 2 n-1\right)=2$

Theorem (4):- $P(n(n-1), 2 n)=2$,

for $n \geq 2$ 
Proof:-

Let $K_{n, n+1}$ be a complete bipartite graph with bipartion $\{X, Y\}, X=\left\{x_{1}, x_{2}, \ldots, x_{n}\right\}, Y=$ $\left\{y_{1}, y_{2}, \ldots, y_{n+1}\right\},|X|=n,|Y|=n+1$,

$V\left(K_{n, n+1}\right)=2 n+1$,

$$
E\left(K_{n, n+1}\right)=n(n-1), d\left(K_{n, n+1}\right)=2 .
$$
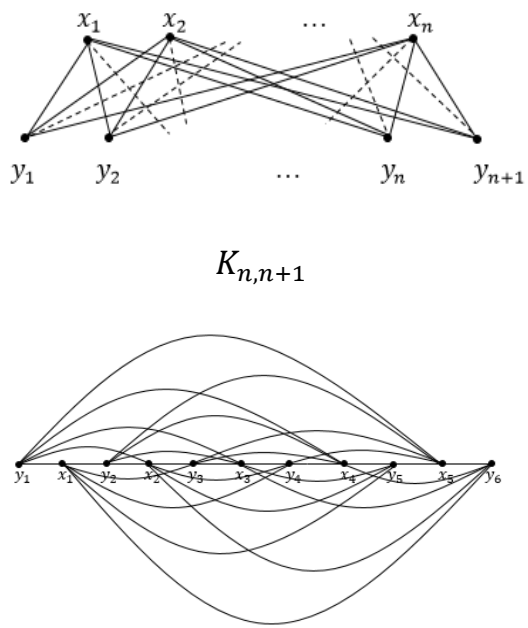

$K_{5,6}$

Let $P=\left(y_{1}, x_{1}, y_{2}, x_{2}, \ldots, y_{n} x_{n}, y_{n+1}\right)$. Then $P$ is alongest path in $K_{n, n+1}$

$$
d(P)=V\left(K_{n, n+1}\right)-1=2 n
$$

$G$ an altereded graph with diameter $d(G)=$ $P(t, d)$ optained from the path $P$ pluse $t$ extra edges such that $G \cong K_{n, n+1}$ then $d(G)=2$ and

$$
\begin{aligned}
t=E\left(K_{n, n+1}\right)-d(P) & =n^{2}+n-2 n \\
& =n(n-1)
\end{aligned}
$$

Now we wanted to prove that

$P(n(n-1), 2 n)=2$ by two ways

1) $d\left(K_{n, n}\right)=2 \rightarrow P(n(n-1), 2 n) \leq 2$

Either $P(n(n-1), 2 n)=1$ or

$P(n(n-1), 2 n)=2$

If $P(n(n-1), 2 n)=1$ this is contradiction, (since the graph not complete).

Then $P(n(n-1), 2 n)=2$

If $n=2$ then from [7] (for $d \geq 3, P(2, d)=$ $\left.\left\lceil\frac{d+1}{3}\right\rceil\right) P(2,4)=\left\lceil\frac{5}{3}\right\rceil=2$
If $n \geq 3$ then $P(n(n-1), 2 n) \leq\left\lceil\frac{2 n-2}{n(n-1)+1}\right\rceil+$ $1=\left\lceil\frac{2 n-2}{n^{2}-n+1}\right\rceil+1$

Since $n \geq 3$

$$
\begin{aligned}
n^{2} \geq 3 n & \rightarrow n^{2}>3 n-2 \\
& \rightarrow n^{2}-n>2 n-2 \\
& \rightarrow n^{2}-n+1>2 n-2
\end{aligned}
$$

Then from equation (1) $P(n(n-1), 2 n) \leq 2$.

Either $P(n(n-1), 2 n)=1$ or

$$
P(n(n-1), 2 n)=2
$$

If $P(n(n-1), 2 n)=1$ this is contradiction, (since the graph not complete).

Then $P(n(n-1), 2 n)=2$

\section{Remark:-}

The symbol " $a \gg b$ " is mean, the number $a$ is too big of number $b$.

\section{Lemma:-}

1) $P\left(t^{\prime}, d^{\prime}\right)<P(t, d)$, if $t^{\prime}-t \gg d^{\prime}-d$

2) $P\left(t^{\prime}, d^{\prime}\right)>P(t, d)$, if $d^{\prime}-d \gg t^{\prime}-t$

Proof:-

1) Let $P(t, d)$ be minimum diameter of an altereded graph $G$ obtained from a path $P=\left(x_{0}, x_{1}, \ldots, x_{d}\right)$ of diameter $d$ with $t$ extra edges and let $P\left(t^{\prime}, d^{\prime}\right)$ be minimum diameter of an altereded graph $G^{\prime}$ obtained from path $P^{\prime}=\left(x_{0}, x_{1}, \ldots, x_{d^{\prime}}\right)$ of diameter $d^{\prime}$ with $t^{\prime}$ extra edges.

Now wanted to prove $P\left(t^{\prime}, d^{\prime}\right)<P(t, d)$, if $t^{\prime}-t \gg d^{\prime}-d$ since $t^{\prime}-t \gg d^{\prime}-d$ this mean

$d^{\prime}-d$ be too small compare with $t^{\prime}-t$,

So, $d^{\prime} \approx d$ and $t^{\prime}$ is greater than $t$, then $P\left(t^{\prime}, d^{\prime}\right)<P(t, d)$, from [12].

In the same way we prove 2 . 


\section{Theorem (5):-}

For $t \geq 2$ and $d=(t+1)+5$, let $G$ and $G^{\prime}$ be two graphs such that $d(G)=P(t, d)$, $G^{\prime}=L(G), d\left(G^{\prime}\right)=P\left(t^{\prime}, G^{\prime}\right)$.

Then $P\left(t^{\prime}, d^{\prime}\right)<P(t, d)$.

Proof:-

Let $m \geq 0, r=1,2,3$ for $t \geq 2, d=(t+1)+$ $5, P(t, d)=3$ from [13] $(P(t, d)=k+2$, for $t \geq 2, k \geq 1$ and $d=k(t+1)+5)$,

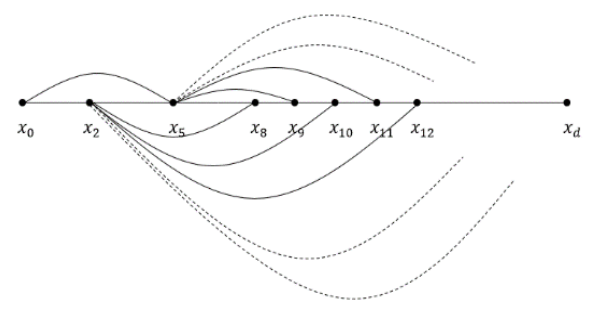

since $t \geq 0, m \geq 0$ and $r=1,2,3$, then

$t=2 m+r+1, d=2 m+r+7$

Let $G^{\prime}$ is line graph of $G$ where $V\left(G^{\prime}\right)=t+d$ and

$$
\begin{gathered}
E\left(G^{\prime}\right)=\frac{1}{2} \sum_{x \in V(P(t, d))}\left(d_{p(t, d)}(x)\right)^{2} \\
-E(P(t, d))
\end{gathered}
$$

$P\left(t^{\prime}, d^{\prime}\right)$ is minimum diameter of an altereded graph $G^{\prime}$

$$
\begin{aligned}
& d^{\prime}=V(G)-1=t+d-1=4 m+2 r+7, \\
& \text { and } t^{\prime}=E\left(G^{\prime}\right)-d^{\prime}=m^{2}+6 m+m r+4 r \\
& t^{\prime}-t=m^{2}+4 m+m r+3 r-1 \\
& d^{\prime}-d=2 m+r
\end{aligned}
$$

Then, $\quad\left(t^{\prime}-t\right)-\left(d^{\prime}-d\right)=m^{2}+2 m+$ $m r+2 r-1 \gg 0$

So, $t^{\prime}-t \gg d^{\prime}-d$

from lemma $\quad P\left(t^{\prime}, d^{\prime}\right)<P(t, d)$

\section{Conclusions}

A minimum diameter of a connected graph obtained from a graph of diameter $d$ after adding $t$ extra edges, this problem called "Edge Addition Problem". We find exact values to problem for some $t$ and $d$ by using some special graph that is:

1. $P(t, 7)=2, t=4,5$

2. $P(5,8)=3$

2. $P\left((n-1)^{2}, 2 n-1\right)=2, n \geq 2$

4. $P(n(n-1), 2 n)=2$, for $n \geq 2$

5. For $t \geq 2$ and $d=(t+1)+5$, let $G$ and $G^{\prime}$ be two graphs such that $d(G)=P(t, d)$, $G^{\prime}=L(G), d\left(G^{\prime}\right)=P\left(t^{\prime}, G^{\prime}\right)$.

Then $P\left(t^{\prime}, d^{\prime}\right)<P(t, d)$.

\section{References}

[1] J. M. Aldous and R. J. Wilson, "Graphs and Application: An Introductory Approach", Springer-Verlag London Berlin Heideberg, 2003.

[2] N. L. Biggs, E. K. Lloyed and R. J. Wilson, "Graph Theory 1736-1936", Clarendon Press. Oxford, 1998.

[3] J.-C. Bermond, N. Homobono and C. Peyyrat, "Large Fault-Tolerant Interconnection Networks", Journal of Graphs and Combinatorics, Vol. 5, PP. 107-123, 1989.

[4] J.-M. Xu, "Topological Structure and Analysis of Interconnection Network" Kluwer Academic Pulbishers, 2001.

[5] W. W. Rouse Ball, Mathematical Recreations and Problems of Pas and Present Time (later entitled Mathematical Recreations and Essays), Macmillan, London, 1892.

[6] F R. K. Chung and M. R. Garey, "Diameter bounds for altered graphs", Journal of Graph Theory. Vol, 8, No 4. PP 511.534, 1984.

[7] A. A. Schoone, H. L. Bodlaender and V. J. Leeunwen "Diameter increase caused by edge deletion" Journal of Graph Theory, Vol 11, No. 3 PP. 409-427, 1987. 
Alaa .A/ Zainab .A

[8] Z. G. Deng and J. M. Xu, "On Diameters of Altered Graphs", Journal of Mathematical study. Vol 37, No.1, PP 35.4L 2004.

[9] H.-X. Ye, C. Yang, J.-M. Xu, "Diameter vulnerability of graphs by edge deletion", Journal of Discrete Mathematics, Vol. 309, PP. 1001-1006, 2009.

[10] A. A. Najim, J. -M. Xu, "On edge Addition of Altered graphs" Journal of University of Science and Technology China Vol 35, No.6, PP, 725-731, 2005.
[11] Y.-Z. Wu, and J. -M. Xu, "Diameters of Altered graph" Journal of Mathematical Research and Exposition, Vol. 26, No. 3. PP 502-508, 2006.

[12] S.A. AL-Bachary "On Edge addition and Edge deletion problems of graph", M.Sc. thesis, university of Basrah, 2009.

[13] S.A.A. AL-Maliky "On Edge addition problems of graph", M.Sc. thesis, university of Basrah, 2013.

\title{
حول مسألة أضافة الحافات مع بعض البيانات
}

\author{
علاء عامر نجم زينب عبد الأمير حزة الحسن \\ قسم الرياضيات \\ جامعة البصرة كلية العلوم
}

السؤالين اقل عدد من الحو اف التي يجب ان تضاف التي الى الثبكة لضمان تأخير الرسالة ضمن حدود فعالة، وكيف سيتم زيادة تأخير رسالة عندما تحدث أخطاء يمكن إعادة كتابة هذه المشكلة على النحو التالي: ما الحد الأدنى للقطر من رسم رسم

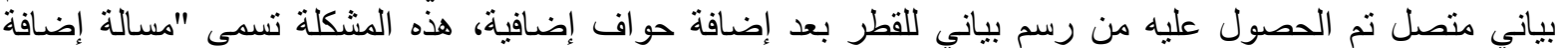
الحافات". في هذا البحث وجدنا بعض القيم الدقيقة للمسألة أعلاه باستخدام بعض البيانات الخاصة (البيان الخطي، بيان التجزئة، بيان التجزئة الكامل). 